\title{
COMPREENSÃO DA METODOLOGIA, ARGUMENTAÇÃO JURÍDICA E RAZÕES DE DECIDIR NA ADI 4277
}

José Sérgio Saraiva

ISSUE DOI: $10.21207 / 1983.4225 .312$

\section{RESUMO}

Trata o presente artigo de uma análise jurídica frente à metodologia, argumentação jurídica e às razões de decidir utilizadas no julgamento da ADI - Ação Direta de Inconstitucionalidade 4277 - pelo Supremo Tribunal Federal ao reconhecer, finalmente, os mesmos diretos e deveres do homem e da mulher que vivem em relação heterossexual às pessoas de mesmo sexo, que vivem em relação homoafetivas. Não foi apreciado o instituto jurídico "casamento e seus efeitos", sendo interpretada a Constituição Federal, no caso em tela, segundo um "Estado Democrático, destinado a assegurar o exercício dos direitos sociais e individuais, a liberdade, a segurança, o bem-estar, o desenvolvimento, a igualdade e a justiça como valores supremos de uma sociedade fraterna, pluralista e sem preconceitos, fundada na harmonia social e comprometida, na ordem interna e internacional, com a solução pacífica das controvérsias", conforme texto previsto no preâmbulo da Constituição Federal. A controvérsia reside, em especial, na atribuição de atuais valores dos direitos fundamentais de "liberdade", "dignidade da pessoa humana", "não discriminação", e prin- 
cípios constitucionais como "igualdade de tratamento e não discriminação", aplicáveis ao homem ou mulher que faça escolha em conviver em união estável entre pessoas mesmo sexo - união estável homoafetiva. A necessária interpretação conforme a Constituição Federal frente ao que dispõe o artigo 226 e parágrafos da Carta e o Código Civil brasileiro em seu artigo 1.723 para fins de reconhecimento de entidade familiar e dela decorrerem todos os direitos e deveres que emanam da união estável entre homem e mulher, também para a união estável entre as pessoas de mesmo sexo, união estável homoafetiva, segundo aqueles direitos fundamentais e princípios. Ao julgar procedentes as ações constitucionais unificando-as na referida "ADI", o Supremo Tribunal Federal deu ao artigo 1.723 do Código Civil brasileiro interpretação conforme a Constituição para rechaçar qualquer entendimento que obste o reconhecimento da "união contínua, pública e duradoura entre pessoas do mesmo sexo como entidade familiar", equiparando, para todos os fins de direito e deveres, as uniões homoafetivas às uniões heteroafetivas. Por outro lado, existem aqueles que enxergam na interpretação, a união estável, hetero ou homoafetiva, como condição jurídica lógica de ser convertida em casamento, observado o disposto no artigo 1.726 do Código Civil brasileiro, fato e direito que não foram apreciados pelo Supremo Tribunal Federal nos respectivos objetos das ações. A interpretação consequente, portanto, é a de que o art. $226, \S 3^{\circ}$ da Carta Magna brasileira obriga a proteção do Estado, passando a reconhecer a união estável homoafetiva como entidade familiar, limites e parâmetros do julgamento.

Palavras-chave: Ação Direta de Inconstitucionalidade. União Estável. Família. Casamento.

\section{BREVE HISTÓRICO DA ADI №. 4277}

Em 25-2-2008, o Governador de Estado do Rio de Janeiro ajuizou perante o Supremo Tribunal Federal a ADPF - Arguição de Descumprimento de Preceito Fundamental que recebeu o $\mathrm{n}^{\circ} .132$.

Pouco mais de quatro meses após, dia 02-7-2009, a PGR - Procuradoria Geral da República ajuizou “ADPF” 178, apensada à ADPF n . 132, justamente pela identidade de matéria e objeto, ou seja, discutia em breve síntese, a "equiparação da união estável entre pessoas do mesmo 
sexo à entidade familiar, preconizada pelo artigo 1.723 do Código Civil brasileiro, desde que preenchidos requisitos semelhantes". ${ }^{147}$

Como fundamento jurídico utilizado pelos dois legitimados, nas duas ações, foram arguidas, dentre outras matérias jurídicas, "o não reconhecimento da união estável entre pessoas do mesmo sexo como entidade familiar violaria direitos fundamentais e princípios: da dignidade humana (art. $1^{\circ}$., III, CF); igualdade e igualdade de tratamento (art. $5^{\circ}$. "caput", $\mathrm{CF}$ ); vedação de discriminação odiosa (art. $3^{\circ}$., IV, CF); da liberdade desdobrada na autonomia de vontade (art. $5^{\circ}$. "caput", CF) e da proteção à segurança jurídica (art. 5०. "caput", CF)".

E se não bastasse isso, fora arguida também, que a omissão legislativa federal sobre o assunto, também violaria os mesmos direitos e princípios, segundo o Governo do Rio de Janeiro na "ADPF" $\mathrm{n}^{\circ} .132$.

Os pedidos das ações constitucionais eram de aplicação analógica do artigo 1.723 do Código Civil brasileiro que disciplina "as uniões afetivas" e que devem ter "interpretação conforme a Constituição", inclusive para fins de interpretação do Estatuto dos Servidores Civis do Estado do Rio de Janeiro, declarando que as decisões judiciais denegatórias de equiparação jurídica das uniões homoafetivas às uniões estáveis afrontam direitos fundamentais.

Como pedido subsidiário do Governador de Estado do Rio de Janeiro, caso não fosse o entendimento da Corte o de recebimento da "ADPF", fosse recebida como "ADI", o que de fato terminou por acontecer, através de decisão do então Presidente do Supremo Tribunal Federal, Ministro Gilmar Mendes, que recebeu as duas ações como ADI - Ação Direta de Inconstitucionalidade 4277.

Assim, o objetivo principal das duas ações era que a Suprema Corte declarasse como obrigatório: a) - o reconhecimento da união homoafetiva como entidade familiar, desde que preenchidos os mesmos requisitos necessários para a configuração da união estável entre homem e mulher; b) e que, os mesmos deveres e direitos originários da união estável entre homem e mulher fossem estendidos aos companheiros nas uniões homoafetivas.

147 AZEVEDO, Álvaro Villaça. Estatuto da família de fato. 2. ed. São Paulo: Atlas, 2002. p. 120. 


\section{DO USO DE METODOLOGIA E DA ARGUMENTAÇÃO JURÍDICA PELOS LEGITIMADOS}

Para interpretar as matérias constitucionais e a legislação regulamentar aplicável, objetos de seus pedidos, valeram os legitimados de fundamentos filosóficos e jurídicos, apontaram afrontas aos direitos fundamentais da pessoa humana, além de exortarem indiretamente em suas razões de fato e de direito, precedentes nacionais e estrangeiros, apontaram os métodos jurídicos ou hermenêuticos clássicos (sistemático lógico ou lógica) e concretista, acompanhados dos princípios da unicidade da Constituição Federal, eficácia integradora, máxima efetividade, interpretação conforme a Constituição Federal, razoabilidade e proporcionalidade, mutação constitucional, dentre outros.

Como contextualização e forma de introdução dos fatos aos pedidos jurídicos, apontavam a necessidade de regulamentação das uniões afetivas, afirmando que não é possível, hoje, ignorar os vínculos homoafetivos, ganhando visibilidade social e jurídica, inclusive no cenário internacional. ${ }^{148}$

E mais: alegavam que os Tribunais de Primeiro Grau do País, já vinham reconhecendo dia-a-dia as relações homoafetivas, direitos e obrigações aos parceiros, como partilha de bens, pensão por morte, dependências em planos de saúde, direito real de habitação, direito à declaração conjunta de imposto de renda, alimentos e até adoção conjunta, dentre outros. ${ }^{149}$

\section{3 \\ DO JULGAMENTO DAS AÇÕES CONSTITUCIONAIS ATRAVÉS DA “ADI” 4277}

No dia 5 de maio de 2011, há quatro anos, o País, através do Supremo Tribunal Federal, vivenciou momento histórico jurídico e social ao ratificar ou chancelar o que os Tribunais inferiores do Poder Judiciário já reconheciam, ou seja, a "equiparação das uniões estáveis entre homossexuais e heterossexuais".

\footnotetext{
148 CHAVES, Marianna. Homoafetividade e direito: proteção constitucional, uniões, casamento e parentalidade - um panorama luso-brasileiro. $1^{\text {a }}$ Ed. Curitiba: Juruá, 2011. 149 CHAVES, Marianna. "Adoção Homoafetiva", em Jornal O Liberal. Belém: 27 de Outubro de 2008.
} 
Registre-se: a Suprema Corte do País não apreciou e nem julgou o instituto do "casamento e seus efeitos".

Tendo como Relator dos Processos, o Ministro Carlos Augusto Ayres Freitas Brito, "Carlos Ayres Brito", fez necessária incursão histórica da noção de "família", através das constituições anteriores, para encontrar evolução jurídica e social.

$\mathrm{Na}$ Constituição de 1937, artigo 124, "A família, constituída pelo casamento indissolúvel, está sob a proteção especial do Estado. Às famílias numerosas serão atribuídas compensações na proporção dos seus encargos." (g.n)

Na Constituição de 1946, através do artigo 163, "A família é constituída pelo casamento de vínculo indissolúvel e terá direito à proteção especial do Estado." (g.n)

Na Constituição de 1967, dispõe o artigo 167, que "A família é constituída pelo casamento e terá direito à proteção dos Poderes Públicos." (g.n) E a Emenda Constitucional 1/1969, mediante o artigo 175 afirma que "A família é constituída pelo casamento e terá direito à proteção dos Poderes Públicos," (g,n)

Finalmente, a vigente Constituição de 1988 não estabelece vinculação com o casamento para definir o conceito de família. Sendo possível identificar, pelo menos, três tipos ou modelos de família, a saber: constituída pelo casamento, pela união estável e, ainda, a que se denomina monoparental.

O Ministro Carlos Ayres Brito, relator dos processos, observando o regimento interno do Supremo Tribunal Federal, foi precedido pela fala da Advocacia-Geral da União (AGU), da Procuradoria Geral da República (PGR) e de diversas entidades representativas de homossexuais, com pedidos de improcedência total para as duas ações pela CNBB Comissão Nacional dos Bispos Brasileiros, representando a Igreja Católica, e a Associação Eduardo Banks.

A "CNBB" sustentou que a Constituição Federal não prevê o tipo de união estável de homoafetivos, estabelece limitação expressa, e ao prever união estável entre homem e mulher, não entre seres do mesmo sexo, não havia lacuna constitucional e via conseguinte, não caberia ao Poder Judiciário apreciar a questão, mas sim ao Poder Legislativo, se for o caso, alterar o correspondente dispositivo constitucional.

Em seguida, o Ministro Carlos Ayres Brito, primeiro a votar acerca das matérias, sustenta primeiro que, a união estável: 
[...] se define por exclusão do casamento civile da formação da família monoparental. É o que sobra dessas duas formatações, de modo a constituir uma terceira via: o tertium genus do companheirismo, abarcante assim dos casais desimpedidos para o casamento civil, ou, reversamente, ainda, sem condições jurídicas para tanto (grifos no original)".

Registra em seu voto que o artigo 1.723 do Código Civil é quase uma cópia do parágrafo $3^{\circ}$ do artigo 226 da Constituição Federal, porém ressaltou que "há uma diferença fundamental": "enquanto a Constituição Federal nos fornece elementos para eliminar uma interpretação reducionista, o Código Civil brasileiro não nos dá elementos, ele sozinho, isoladamente, para isolar dele uma interpretação reducionista" ${ }^{150}$. Passase a citar a norma civil:

Art. 1.723. É reconhecida como entidade familiar a união estável entre o homem e a mulher, configurada na convivência pública, contínua e duradoura e estabelecida com o objetivo de constituição de família.

$\S 1^{\circ}$ A união estável não se constituirá se ocorrerem os impedimentos do art. 1.521; não se aplicando a incidência do inciso VI no caso de a pessoa casada se achar separada de fato ou judicialmente.

$\S 2^{\circ}$ As causas suspensivas do art. 1.523 não impedirão a caracterização da união estável.

Registra mais, que "o texto em si do artigo 1.723 é plurissignificativo, comporta mais de uma interpretação" e "por comportar mais de uma interpretação, sendo que, uma delas se põe em rota de colisão com a Constituição, estou dando uma interpretação conforme, postulada em ambas as ações", sustenta ele.

Sustenta que a Constituição Federal ao registrar o termo "família" em vários dispositivos, nela não está contida a proibição de sua formação a partir de uma relação homoafetiva.

150 Disponível em <http://www.stf.jus.br/arquivo/cms/noticiaNoticiaStf/anexo/ADI4277 revisado.pdf>. 
Portanto, trata-se de interpretação conforme a constituição, ou seja, interpretação gramatical ou literal, além de apontar a Constituição para o fato concreto, valendo-se do método hermenêutico ou concretizador.

Prossegue o Ministro, em sua argumentação, afirmando que a "Constituição Federal de 1967, apontou que a família se constituía somente pelo casamento, e a Carta de 1988, evoluiu para dar ênfase à instituição da família, independentemente da preferência sexual de seus integrantes" (g.n).

Argumentou, também, que a "Constituição Federal, art. $3^{\circ}$, inciso IV, veda qualquer discriminação em virtude de sexo, raça, cor e que, nesse sentido, ninguém pode ser diminuído ou discriminado em função de sua preferência sexual". E em relação ao "sexo das pessoas, salvo disposição contrária, não se presta para desigualação jurídica", registrou o Ministro Relator, para concluir que qualquer depreciação da união estável homoafetiva colide, portanto, com o inciso IV do artigo $3^{\circ}$ da Carta Maior.

Prossegue, ainda, afirmando que Constituição Federal, "age com intencional silêncio quanto ao sexo", respeitando a privacidade e a preferência sexual das pessoas. A Constituição Federal "não obrigou nem proibiu o uso da sexualidade" e assim é, um direito subjetivo da pessoa humana, perfilha-se ao lado das clássicas liberdades individuais.

A preferência sexual, seria um "autêntico bem da humanidade", afirmou ainda o Ministro, observando que, "assim como o heterossexual se realiza pela relação heterossexual, o homoafetivo tem o direito de ser feliz relacionando-se com pessoa do mesmo sexo".

Por fim, o Ministro disse que o artigo 1.723 do Código Civil deve ser interpretado conforme a Constituição, para dele excluir: "qualquer significado que impeça o reconhecimento da união contínua, pública e duradoura entre pessoas do mesmo sexo como 'entidade familiar', entendida esta como sinônimo perfeito de "família".

Em momento algum, enfrentou ou apreciou as questões que orbitam o instituto do casamento e seus efeitos, civil ou religioso.

Pode-se compreender, então, salvo melhor entendimento jurídico, que o Ministro "Carlos Ayres Brito", usou como argumento o princípio da igualdade e do tratamento igual para julgar as duas ações totalmente procedentes. 
Não se pode deixar de registrar que para efeitos de debates discordaram em parte os Ministros Marco Aurélio, Carmem Lúcia, Menezes de Direito???, Ricardo Lewandowski, sobre a possibilidade de conversão da união estável em casamento de pessoas de mesmo sexo, constituiria condição "sine qua non" para o reconhecimento de entidade familiar, sob pena de ter-se mera relação de concubinato.

Portanto, não haveria como enquadrar a união entre pessoas do mesmo sexo em nenhuma dessas espécies de família, quer naquela constituída pelo casamento, quer na união estável, estabelecida a partir da relação entre um homem e uma mulher, quer, ainda, na monoparental.

Para o Ministro Ricardo Lewandowiski, "não há como cogitarse de uma de mutação constitucional ou mesmo de proceder-se a uma interpretação extensiva do dispositivo em foco, diante dos limites formais e materiais que a própria Lei Maior estabelece no tocante a tais procedimentos, a começar pelo que se contém no art. $60, \S 4^{\circ}$, III, da Carta, o qual erige a "separação dos Poderes" à dignidade de "cláusula pétrea", que sequer pode ser alterada por meio de emenda constitucional."

Prossegue afirmando que a interpretação jurídica não pode exceder os limites objetivamente delineados nos parâmetros normativos, o que equivale dizer interpretação conforme a Constituição Federal. Deve enquadrar-se, juridicamente, o convívio duradouro e ostensivo entre pessoas do mesmo sexo, fundado em laços afetivos, equivalente à "relação homoafetiva“.

Embora essa relação não se caracterize como uma união estável, afirma o Ministro:

[...] penso que se está diante de outra forma de entidade familiar, um quarto gênero, não previsto no rol encartado no art. 226 da Carta Magna, a qual pode ser deduzida a partir de uma leitura sistemática do texto constitucional e, sobretudo, diante da necessidade de dar-se concreção aos princípios da dignidade da pessoa humana, da igualdade, da liberdade, da preservação da intimidade e da nãodiscriminação por orientação sexual aplicáveis às situações sob análise. (g.n) 
Não resta dúvida que aqui, o Ministro Ricardo Lewandowiski, utilizou o método tópico, problemático, ou seja, parte do problema concreto para a norma.

É possível ser entendida a união estável de pessoas do mesmo sexo que se projetam no tempo e publicamente, na medida em que constitui um dado da realidade fenomênica (DIAS, 2007) e, por consequência, não são proibidas pelo ordenamento jurídico, devem ser reconhecidas pelo Direito como entidade familiar (DIAS, 2011), valendo-se do que diziam os jurisconsultos romanos, "ex facto oritur jus", ou seja, "o direito é gerado dos fatos", mas não converter em casamento, cuja interpretação não foi extensiva e capaz de permitir aplicação do artigo 1.726 do Código Civil para as uniões estáveis de pessoas de mesmo sexo, reconhecidas sim, como famílias homoafetivas, conforme interpretação, pelo menos através da ADI 4277.

Registre-se, para conceituar, juridicamente, "a relação duradoura e ostensiva entre pessoas do mesmo sexo", já que não há previsão normativa expressa a ampará-la, seja na Constituição e mesmo na legislação ordinária, outra alternativa não havia senão lançar mão da "integração analógica". ${ }^{151}$

Nos ensinamentos de Canotilho: "A integração existe quando determinadas situações: (1) que se devem considerar constitucionalmente reguladas; (2) não estão previstas; (3) e não podem ser cobertas pela interpretação, mesmo extensiva, de preceitos constitucionais (considerados na sua letra e no seu ratio)". ${ }^{152}$

Uma lacuna normativo-constitucional só existe quando se verifica uma incompletude contrária ao 'plano' de ordenação constitucional. ${ }^{153}$

Em outras palavras, prossegue o Canotilho:

[...] a lacuna constitucional autônoma surge quando se constata a ausência, no complexo normativo-

${ }^{151}$ GONÇALVES, Carlos Roberto. Direito civil brasileiro: Direito de família. São Paulo: Saraiva, 2005. v. IV, p 75.

152 CANOTILHO, José Joaquim Gomes. Constituição e Teoria da Constituição, $2^{\mathrm{a}}$ ed. Coimbra, Livraria Amedina, 1998. p, 15.

${ }^{153}$ BARROSO, Luís Roberto. $\mathrm{O}$ controle de constitucionalidade no direito brasileiro: exposição sistemática da doutrina e análise crítica da jurisprudência. 5. ed. rev. e atual. São Paulo: Saraiva, 2011. p, 233. 
constitucional, de uma disciplina jurídica, mas esta pode deduzir-se a partir do plano regulativo da constituição e da teleologia da regulamentação constitucional. ${ }^{154}$

Daí ser possível indagar afinal: o rol do art. 226 da Constituição Federal é taxativo ou exemplificativo?

A maioria da doutrina entende ser exemplificativa em razão da "da natureza aberta das normas constitucionais" $" 155$, perfilhando os seguintes entendimentos, adiante:

Em primeiro lugar, o $\S 4^{\circ}$ do art. 226 adotando o termo: "também", teria o significado de igualmente, da mesma forma, outrossim de inclusão de fato sem exclusão de outros. Então, se dois forem os sentidos possíveis (inclusão ou exclusão), deve ser prestigiado o que melhor responda à realização da dignidade da pessoa humana, sem desconsideração das entidades familiares reais não explicitadas no texto.

Posteriormente, mas com igual importância, vejamos na íntegra o preâmbulo da Carta e o Artigo 226 e $\$ 4^{\circ}$ :

Preâmbulo da CF: "Nós, representantes do povo brasileiro, reunidos em Assembléia Nacional Constituinte para instituir um Estado Democrático, destinado a assegurar o exercício dos direitos sociais e individuais, a liberdade, a segurança, o bem-estar, o desenvolvimento, a igualdade e a justiça como valores supremos de uma sociedade fraterna, pluralista e sem preconceitos, fundada na harmonia social e comprometida, na ordem interna e internacional, com a solução pacífica das controvérsias, promulgamos, sob a proteção de Deus, a seguinte CONSTITUIÇÃO DA REPÚBLICA FEDERATIVA DO BRASIL".

Art. 226. A família, base da sociedade, tem especial proteção do Estado.

\footnotetext{
${ }^{154}$ CANOTILHO, José Joaquim Gomes. Constituição e Teoria da Constituição, $2^{\mathrm{a}}$ ed. Coimbra, Livraria Amedina, 1998. p, 16.

155 BARROSO, Luís Roberto. $\mathrm{O}$ controle de constitucionalidade no direito brasileiro: exposição sistemática da doutrina e análise crítica da jurisprudência. 5. ed. rev. e atual. São Paulo: Saraiva, 2011. p, 235.
} 
$\S 1^{\circ} \mathrm{O}$ casamento é civil e gratuita a celebração.

$\S 2^{\circ} \mathrm{O}$ casamento religioso tem efeito civil, nos termos da lei.

$\S 3^{\circ}$ Para efeito da proteção do Estado, é reconhecida a união estável entre o homem e a mulher como entidade familiar, devendo a lei facilitar sua conversão em casamento.

$\S 4^{\circ}$ Entende-se, também, como entidade familiar a comunidade formada por qualquer dos pais e seus descendentes.

$\S 5^{\circ}$ Os direitos e deveres referentes à sociedade conjugal são exercidos igualmente pelo homem e pela mulher.

$\S 6^{\circ} \mathrm{O}$ casamento civil pode ser dissolvido pelo divórcio, após prévia separação judicial por mais de um ano nos casos expressos em lei, ou comprovada separação de fato por mais de dois anos.

$\S 7^{\circ}$ Fundado nos princípios da dignidade da pessoa humana e da paternidade responsável, o planejamento familiar é livre decisão do casal, competindo ao Estado propiciar recursos educacionais e científicos para o exercício desse direito, vedada qualquer forma coercitiva por parte de instituições oficiais ou privadas.

$\S 8^{\circ} \mathrm{O}$ Estado assegurará a assistência à família na pessoa de cada um dos que a integram, criando mecanismos para coibir a violência no âmbito de suas relações. [...]

Ainda assim, não se vislumbra interpretação capaz de permitir a conversão em casamento decorrente da união estável entre pessoas do mesmo sexo, mas inegável que constitui nova e igual forma de família, devendo ser respeitada em todos os direitos e obrigações fundamentais da pessoa humana.

Em abono ao entendimento acima, o Ministro Ricardo Lewandowiski, discorre em seu voto, que "escapar da evidência de que a união homossexual, em nossos dias, é uma realidade de elementar constatação empírica, a qual está a exigir o devido enquadramento jurídico, visto que dela resultam direitos e obrigações que não podem colocar-se à margem 
da proteção do Estado, ainda que não haja norma específica a assegurálos". 156

E ainda observou que "direito e moral" devem ter critérios distintos, mas caminhar juntos.

Entretanto, embora ressalvasse a forte influência da moral sobre o direito, disse que "concepções morais não podem determinar o tratamento dispensado pelo Estado aos direitos fundamentais. As garantias de liberdade religiosa e do Estado laico impedem que concepções morais religiosas guiem o tratamento estatal dispensado a direitos fundamentais, tais como o direito à dignidade da pessoa humana, o direito à autodeterminação, à privacidade e o direito à liberdade de orientação sexual". ${ }^{157}$

Votou pela procedência das duas ações a Ministra Ellen Gracie, acompanhando integramente o Relator, ministro Carlos Ayres Britto; deixou sua posição jurídica clara destacando que a família exige a "durabilidade da relação, a não clandestinidade e a continuidade, além da ausência de impedimento". Assinalou que a evolução do direito que cabe aos homossexuais teve início há anos, "já no Código napoleônico, que descriminalizou a prática homossexual, até então considerada um delito". .58

Na sua compreensão, essa evolução tem também outras "barreiras" a serem vencidas para que se consiga a "igualdade plena". E "uma sociedade decente é uma sociedade que não humilha seus integrantes".

E finalizou seu entendimento dizendo que o Supremo "restitui [aos homossexuais] o respeito que merecem, reconhece seus direitos, restaura a sua dignidade, afirma a sua identidade e restaura a sua liberdade".

Seu posicionamento permite concluir que usou da "interpretação valorativa" para concluir seu voto.

O Ministro Marco Aurélio Mello, para concluir e lavrar seu voto, utilizou-se do princípio da dignidade da pessoa humana "ostentando a

156 Disponível em <http://s.conjur.com.br/dl/voto-ricardo-lewandowski-uniao. pdf>

${ }^{157}$ BARROSO, Luís Roberto. O controle de constitucionalidade no direito brasileiro: exposição sistemática da doutrina e análise crítica da jurisprudência. 5. ed. rev. e atual. São Paulo: Saraiva, 2011. p, 75

158 CHAVES, Marianna. Homoafetividade e direito: proteção constitucional, uniões, casamento e parentalidade - um panorama luso-brasileiro. $1^{\text {a }}$ Ed. Curitiba: Juruá, 2011. p, 106. 
qualidade de fundamento maior da República", estabelecendo uma hierarquia, estaria a dignidade da pessoa humana no ápice da pirâmide valorativa para fins de interpretação constitucional.

Destaca as opiniões doutrinárias que asseveram tratar-se do "valor dos valores", do "ponto de Arquimedes no Estado constitucional", de modo que a importância enquanto fonte autônoma de obrigações e direitos, não poderiam ser negligenciados. E justamente com base nesses fundamentos, conclui o Ministro que "é obrigação constitucional do Estado reconhecer a condição familiar e atribuir efeitos jurídicos às uniões homoafetivas."

Prossegue o Ministro dizendo que "entender contrário discrepa, a mais não poder, das garantias e direitos fundamentais, dá eco a preconceitos ancestrais, amesquinha a personalidade do ser humano e, por fim, desdenha o fenômeno social, como se a vida comum com intenção de formar família entre pessoas de sexo igual não existisse ou fosse irrelevante para a sociedade".

Salienta ainda, que "ao Estado é vedado obstar que os indivíduos busquem a própria felicidade, a não ser em caso de violação ao direito de outrem, o que não ocorre na espécie".

Também votou pela procedência das duas ações, deixando claro que usou também o "princípio como meio de integração-interpretação do sistema".

O Ministro Gilmar Ferreira Mendes (Gilmar Mendes), igualmente votando pela procedência das duas ações, ressaltou "que se limitava a reconhecer a existência legal da união homoafetiva por aplicação analógica do texto constitucional, sem se pronunciar sobre outros desdobramentos".

Para ele, "pretender regular isso é exacerbar demais nossa vocação de legisladores positivos, com sério risco de descarrilarmos, produzindo lacunas". E o fato de a Constituição proteger a união estável entre homem e mulher não significa uma negativa de proteção à união civil estável entre pessoas do mesmo sexo, arremata, demonstrando que aplicou as regras analógicas do texto constitucional.

E o Ministro Joaquim Benedito Barbosa Gomes (Joaquim Barbosa), destaca no seu voto que a Constituição "estabelece, de forma cristalina, o objetivo de promover a justiça social e a igualdade de tratamento entre os cidadãos". E entre "os objetivos fundamentais da República", estão o de promover o bem de todos sem preconceitos de raça, sexo, cor, 
idade ou quaisquer outras formas de discriminação, na mesma linha de argumentação do Relator Ministro Carlos Ayres Brito.

Desta, ainda, o Ministro que "a Carta Constitucional não cita, nem proíbe o reconhecimento jurídico das uniões homoafetivas, mas a própria Carta estabelece que o rol de direitos fundamentais do cidadão não se esgota naqueles expressamente elencados por ela."

Percebe então que o Ministro se valeu dos princípios da dignidade humana, igualdade e não discriminação, como metodologia de interpretação constitucional e razões de decidir.

\section{CONSIDERAÇÕES FINAIS}

Assim, pode-se concluir que, dentre os vários métodos, argumentações jurídicas e as razões de decidir na ADI 4277, a Corte Suprema, apesar de alguns pequenos entendimentos destoantes entre os Ministros, não buscou somente reconhecer uma "união estável homoafetiva", através de interpretação extensiva do $\S 3^{\circ}$ do art. 226, mas uma "união homoafetiva estável", mediante um processo de integração analógica, o que quer dizer, revelar-se e confirmar-se, por esse método, outra espécie de entidade familiar, que se coloca ao lado daquelas formadas pelo casamento, pela união estável entre um homem e uma mulher e por qualquer dos pais e seus descendentes, claramente expressas no texto constitucional.

Ao empregar, também, como se viu, o instrumento metodológico da integração, não se fez substituir a vontade do constituinte por outra arbitrariamente escolhida, mas apenas, tendo-se em conta a existência de um vácuo normativo, e senão procurar reger uma realidade social e internacional superveniente a essa vontade, ainda que de forma provisória, ou seja, até que o Poder Legislativo lhe dê efetivamente o adequado tratamento legislativo, motivos pelos quais não se vê na interpretação a extensão possível para conversão da união estável homoafetiva em casamento, até agora, considerando que não foi analisado o instituto "casamento e seus reflexos", portanto, inaplicável o artigo 1726 do Código Civil brasileiro.

O pronunciamento do Supremo Tribunal Federal, através da ADI 4277, possibilita uma visibilidade social e jurídica, não só em âmbito nacional e marca cadência com ordem internacional como bem ressaltaram todos os Ministros da Corte, na medida em que vários outros países 
tradicionais já admitem e reconhecem a união estável homoafetiva, inclusive como nova família ao lado das demais reconhecidas expressamente no texto constitucional.

\section{REFERÊNCIAS BIBLIOGRÁFICAS}

AZEVEDO, Álvaro Villaça. Estatuto da família de fato. 2. ed. São Paulo: Atlas, 2002.

BARROSO, Luís Roberto. O controle de constitucionalidade no direito brasileiro: exposição sistemática da doutrina e análise crítica da jurisprudência. 5. ed. rev. e atual. São Paulo: Saraiva, 2011.

CANOTILHO, José Joaquim Gomes. Constituição e Teoria da Constituição, $2^{a}$ ed. Coimbra, Livraria Amedina, 1998.

CHAVES, Marianna. "Adoção Homoafetiva", em Jornal O Liberal. Belém: 27 de Outubro de 2008. . Homoafetividade e direito: proteção constitucional, uniões, casamento e parentalidade - um panorama luso-brasileiro. $1^{\mathrm{a}} \mathrm{Ed}$. Curitiba: Juruá, 2011.

Homoafetividade e direito: proteção constitucional, uniões, casamento e parentalidade - um panorama luso-brasileiro. $2^{\mathrm{a}}$ ed. rev., atual. e ampl. Curitiba: Juruá, 2011.

"O STF e as uniões homoafetivas", em A Semana - Política, Economia e Comportamento. Ano 13, n. 14, 13 a 20 de Maio de 2010, p. 22.

DIAS, Maria Berenice. Manual de Direito das Famílias.4. ed. rev., atual. e ampl. São Paulo: Editora Revista dos Tribunais, 2007.

DINIZ, Maria Helena. Curso de direito civil brasileiro, vol. 5: Direito de família. 15 ed., rev. São Paulo: Saraiva, 1999.

GOMES, Orlando. Direito de família. 10. ed. Rio de Janeiro: Forense, 1998.

GONÇALVES, Carlos Roberto. Direito civil brasileiro, vol. VI: Direito de família. São Paulo: Saraiva, 2005.

MONTEIRO, Washington - de Barros. Curso de direito civil, vol.II: direito de família. 37. ed., rev. e atual. por Regina Beatriz Tavares da Silva. São Paulo: Saraiva, 2004.

PACE, Maria Clayde Alves. "Casamento civil entre pessoas do mesmo sexo: um breve estudo sobre o direito fundamental de acesso ao modelo de família matrimonializado efetivado pela 
hermenêutica constitucional", em Apontamentos críticos para o direito civil brasileiro contemporâneo/ Eroulths Cortiano Junior, Jussara Maria Leal de Meirelles, Luiz Edson Fachin, Paulo Nalin (coords.). Curitiba: Juruá, p. 191 - 210, 2008.

PEREIRA, Caio Mário da Silva. Instituições de direito civil, vol. V: Direito de família. 16. ed., rev. e atual. por Tânia da Silva Pereira. Rio de Janeiro: Forense, 2007.

VECCHIATTI, Paulo Roberto Iotti. Manual da Homoafetividade: da possibilidade jurídica do casamento civil, da união estável e da adoção por homossexuais. São Paulo: Editora Método, 2008. 